\title{
FEEDING BEHAVIOR IN THE ANT RHOPALOTHRIX BIROI SZABÓ
}

\author{
By EDWARD O. WILSON \\ Biological Laboratories, Harvard University
}

Through recent work on the biology of the tribe Dacetini ${ }^{1}$, it is now known that the members of this large, cosmopolitan group are generally predators which feed primarily on collembolans and secondarily on other softbodied arthropods. Most are slow-moving and rely on stealth and the trap-like action of their mandibles in securing their prey. It has been an open question whether other groups of ants morphologically convergent to the dacetines, such as the tribe Basicerotini and genera Myrmoteras and Stegomyrmex, show similar feeding behavior. Exclusively tropical distributions, scarceness, and small colony size have made the study of living material in these groups prohibitively difficult in the past. I was fortunate, therefore, during a recent visit to New Guinea to be able to find and study in life the basicerotine species Rhopalothrix biroi.

This species was encountered in lowland rainforest in the vicinity of the lower Busu River, near Lae. Here it is relatively common, turning up regularly in soil-litter berlesates and as strays under rotting logs on the ground. As in other Rhopalothrix species I have collected, colonies were exceedingly difficult to locate. I found only one (my accession no. 987), occupying indistinct chambers about a quarter-inch below the surface in loose soil under a rotting log. The colony was uncovered and partly scattered by random scraping of the soil surface in search for other ants. Thirty-four workers, two males, and a quantity of pupae and all stages of larvae were retrieved. Colony cohesion was good, and there was no trouble in

${ }^{1}$ See Brown, W. L., 1953, Ann. Ent. Soc. Amer., 46: 465-471; and Wilson, E. O., op. cit: 479-495. 
getting the ants to move into the brood chambers of a small plaster-of-paris Janet nest. The workers had soon massed the brood and were back out foraging in the food chamber.

During the next several days the following small animals were introduced alive into the food chamber: nematodes (possibly confused with small enchytraeid annelids), mites, spiders, isopods, millipedes, symphylans, entomobryid and onychiurid collembolans, campodeids, homopteran and heteropteran nymphs, fly larvae, beetle larvae and adults, and an adult minor worker of the ant genus Pheidole. The Rhopalothrix showed definitely neutral or aversive behavior toward the isopods, millipedes, onychiurid collembolans, beetle adults, and Pheidole. The nematodes, mites, and homopteran nymphs were completely overlooked or at least no definite reaction was recorded. One worker seized a cyclorrhaphan fly larva but was not able to subdue it. The remaining prey offered - spiders, symphylans, entomobryid collembolans, campodeids, and heteropteran nymphs - were captured and then eaten by the workers or larvae or both. Of this last group, entomobryids were the most quickly captured, and this could be explained on the basis of their relatively small size and feeble strength. My observations are too limited to establish prey specificity within the accepted group, but I believe that entomobryids may have formed the principal dietary staple of the colony in nature, since these insects were far and away the most abundant and accessible arthropods in the vicinity of the nest. Otherwise, if any generalization is to be made about food preference, it is probably safest to say that this species of Rhopalothrix accepts a wide variety of soft-bodied arthropods and rejects other animals that are either hard-bodied or possess repugnant odors.

Hunting behavior of the observation colony was very similar to that we have seen in the short-mandibulate dacetines. The workers foraged with the same slow, deliberate gait, but in addition punctuated by little total halts in the movement, one to three a second, making them appear to jerk along. On contacting potential prey 
the ants "froze" in their movement, drew their antennae part way back (but not all the way against the head), and opened their mandibles maximally, that is, to the extent where the tips were about as far apart as the width of the clypeus. This was followed by a slow, cautious movement toward the prey. On one occasion a worker was seen to lunge and snap at an entomobryid immediately upon making contact, but careful stalking is probably the rule, as it is in the short-mandibulate dacetines.

Prey were carried into the brood chamber directly after capture; only once was a worker seen to feed on an entomobryid at the spot of capture. Captured animals were either left on the brood chamber apart from the larvae, or else placed immediately among the larvae, which fed on it directly, ponerine fashion. The adults fed separately or simultaneously with the larvae on the same animal, as I have observed many times in the dacetine genus Smithistruma.

While they behaved in an alert, aggressive manner toward potential prey, the Rhopalothrix reacted toward potential enemies, such as larger staphylinid beetles, by lowering the head, retracting the antennae entirely, and keeping the mandibles closed. One worker, knocked over by a beetle walking past, was seen to draw in all of its appendages and feign death.

The workers were very solicitous of the brood, washing it and moving it about constantly. They were in fact more attentive in this way than any dacetine genera I have studied. Adult oral trophallaxis was observed twice; the workers faced one another and twisted their heads slightly sidewise to approximate mouthparts. The adults also licked one another's bodies constantly. Once I saw a worker standing rigidly still, while a second worker curled around its upraised head and gave the mouthparts, gula, and prosternum a thorough washing. Adult transport was observed once. The transporter gripped the transportee's pedicel from below, while the transportee folded in its appendages pupal fashion. Later the transporter shifted its grip so that one mandible rested on the gaster. 

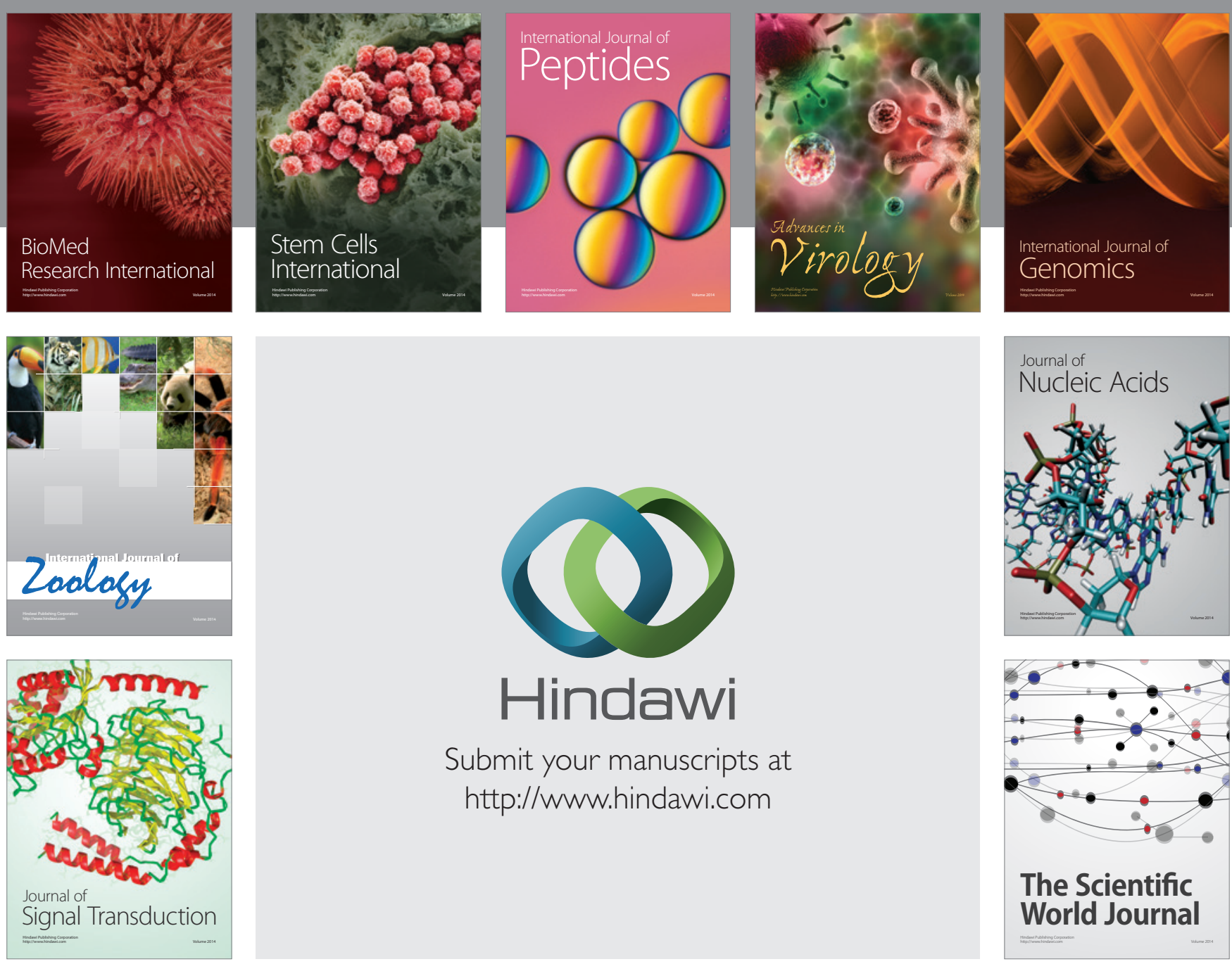

Submit your manuscripts at

http://www.hindawi.com
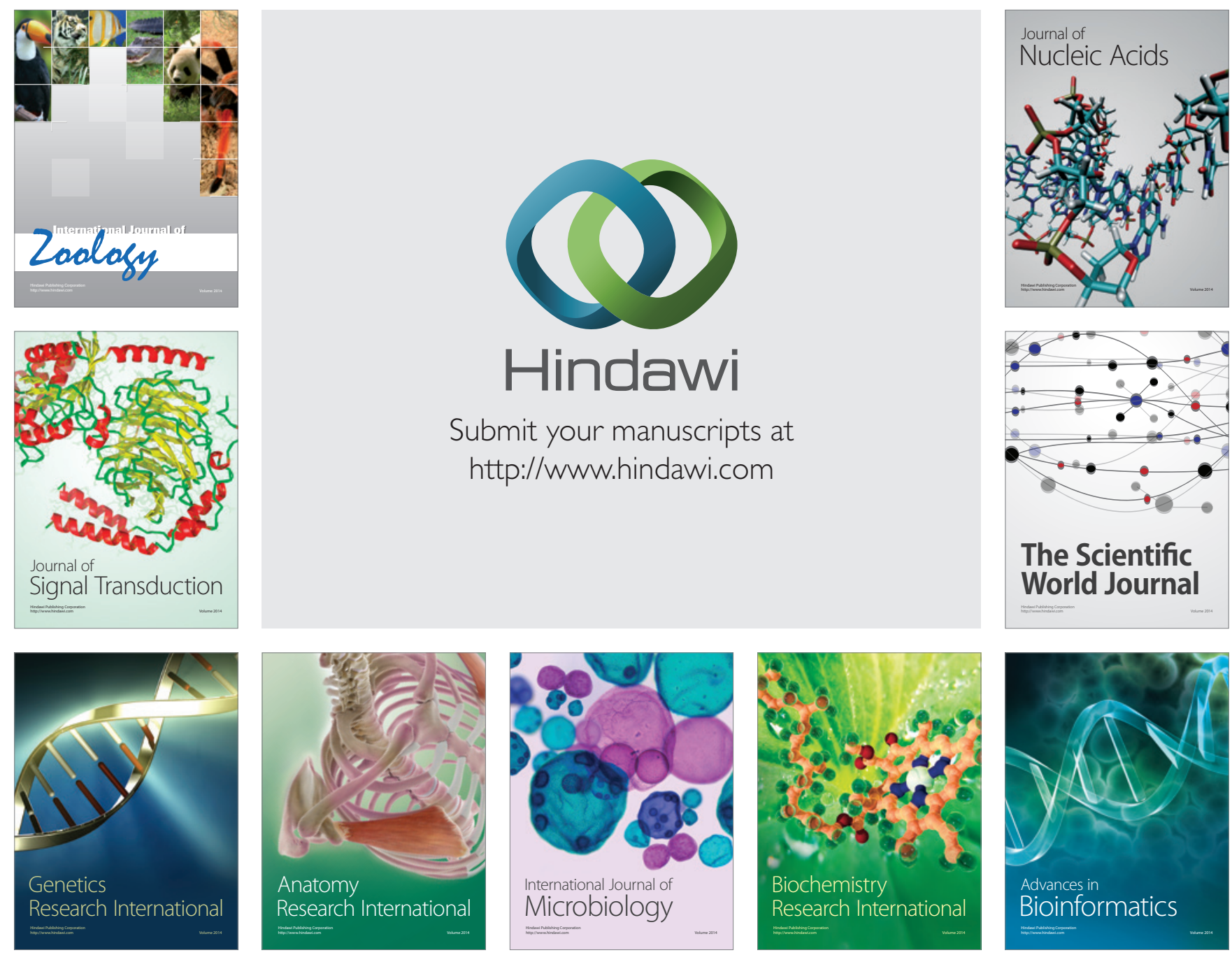

The Scientific World Journal
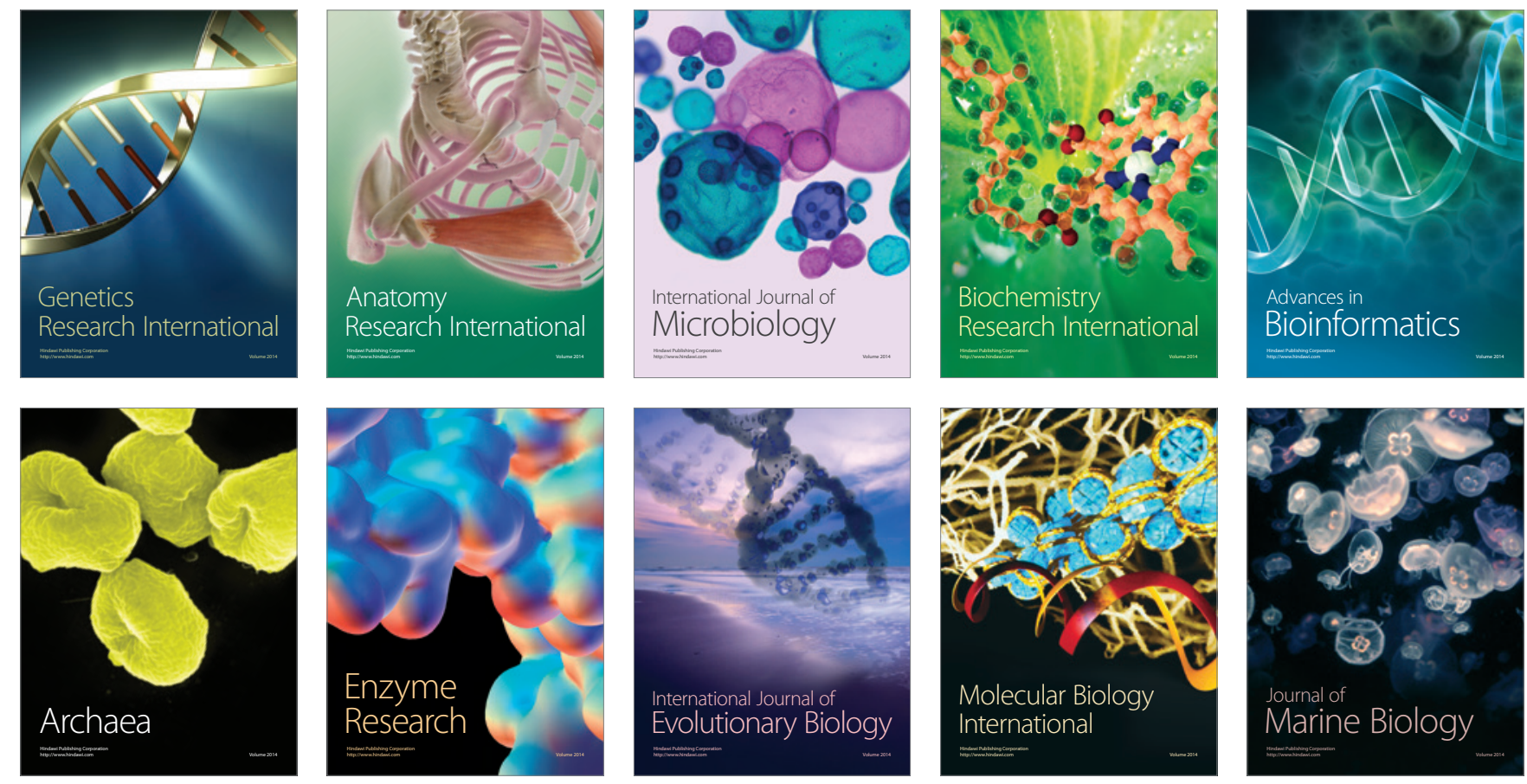